Brit. J. prev. soc. Med. (1974), 28, 127-132

\title{
Attitude of the individual to his own body weight
}

\author{
MARGARET ASHWELL AND LINDSEY ETCHELL \\ Clinical Research Centre, Watford Road, Harrow, Middlesex HAI $3 U$ J and \\ Consumers' Association, 14 Buckingham Street, London WC2N 6DS
}

\section{SUMMARY}

A random height and weight survey in a London Borough showed that overweight people were most accurate in the assessment of their weight and underweight people were the least accurate. Overweight women were more aware of their size than overweight men.

Overweight women had made more attempts to lose weight than overweight men. There were no significant differences between overweight women of different age or class groups. Men in social classes $A$ and $B$ were more likely than men in other groups to have tried to lose weight.

These results show that the high prevalence of overweight associated with older and lower social class women cannot be explained by the fact that they are unaware of their size and only partly explained by the fact that they have not made attempts to lose weight.

The results of a second survey conducted among Consumers' Association members showed that the weights considered as ideal by these people corresponded very well with the ideal weights given by life insurance tables.

\section{INTRODUCTION}

A previous study of two general practices in London (Silverstone, 1968) showed that obesity was more prevalent in women than in men, increased with age in both sexes, and was more prevalent in women of the lower social classes. Montegriffo's (1968) study of British Petroleum employees also showed the greater prevalence of obesity in the older age groups. We investigated attitudes to body weight to evaluate the self-assessment an individual makes of body weight and also to see whether he has ever tried to change it. We wanted to see if the people who are overweight have become so simply because (1) they do not realize that they are overweight, or (2) they do not care that they are overweight, i.e., they have not made attempts to lose weight.

The other point that we wanted to determine was whether people aim at sensible target weights when they try to lose weight. The ideal or desirable weights usually quoted are those derived from the mortality figures of American life insurance companies (Metropolitan Life Insurance Company, 1959), i.e., the ideal weight for a particular height is defined as the weight at which mortality is lowest. Our intention was to ask a group of people what weight they would ideally like to be, and to compare these personal ideal weights with those given by the mortality data.

\section{METHODS}

This work was undertaken during the preparation of the Which? Slimming Guide and involved two separate surveys.

\section{The RICHMOND SURVEY}

In this survey, the heights and weights of a random sample of the population of the London Borough of Richmond were recorded (for further details of the survey see Baird, Silverstone, Grimshaw, and Ashwell (1974)). The subjects were weighed and measured, and asked to record whether they considered themselves to be underweight, overweight or a suitable weight for their height and to say whether they had ever tried to lose weight. Age and occupation were also recorded. In the case of married women, the husband's occupation was recorded. Social class was determined according to the social grading of the National Readership Survey (Monk, 1971). 
The Consumers' Association Survey

This was a much larger survey but was not a random sample because it was clearly biased in favour of subjects with weight problems. A request was made in the Consumers' Association magazine Which? to any reader who had had experience of slimming. A questionnaire covering many aspects of slimming was sent out and 2,333 replies were received. Among other things, the respondents were asked to state their current weight and the weight they would ideally like to be. It was possible to analyse these data for 2,173 respondents.

\section{Classification of Weights}

The heights and weights of the participants of both the first and second surveys were analysed and classified in the same way. The mean of the 'medium frame' of the Metropolitan Life Tables was taken as the standard weight, $\mathbf{M}$, for a given height. A range $10 \%$ either side of $M$ was classified as suitable weight, a range $11-20 \%$ outside as mild over or underweight, a range $21-30 \%$ outside as moderate over or underweight, and greater than $30 \%$ outside was taken as severe over or underweight.

The actual heights and weights of the participants of the first survey and the stated heights and weights of the participants of the second survey were classified in this way. The weights given as 'ideal' by the people in the second survey were also thus classified.

\section{Statistics}

Tests of significance were performed using the $\chi^{2}$ test.

\section{The Richmond SURVEY}

\section{RESULTS}

Although the heights and weights of 1,334 people (794 women and 540 men) were measured in this survey, it was possible to obtain the records of only 1,059 people (619 women and 440 men) concerning their attitude to their body weight. Table I shows

TABLE I

CLASSIFICATION BY WEIGHT CLASS: THE RICHMOND SURVEY

\begin{tabular}{|c|c|c|c|c|c|c|}
\hline \multirow[b]{2}{*}{ Weight Class } & \multicolumn{2}{|c|}{ All } & \multicolumn{2}{|c|}{ Males } & \multicolumn{2}{|c|}{ Females } \\
\hline & No. & $\%$ & No. & $\%$ & No. & $\%$ \\
\hline $\begin{array}{cc}\begin{array}{c}\text { Underweight } \\
\text { Severe }\end{array} & \ldots \\
\text { Moderate } & \ldots \\
\text { Mild } & \ldots\end{array}$ & $\begin{array}{r}1 \\
25 \\
129\end{array}$ & $\begin{array}{r}0 \\
2 \\
12\end{array}$ & $\begin{array}{r}0 \\
12 \\
50\end{array}$ & $\begin{array}{r}\mathbf{0} \\
\mathbf{3} \\
\mathbf{1 1}\end{array}$ & $\begin{array}{r}1 \\
13 \\
79\end{array}$ & $\begin{array}{r}0 \\
2 \\
13\end{array}$ \\
\hline $\begin{array}{l}\text { Suitable weight } \\
\text { Overweight }\end{array}$ & 527 & 50 & 219 & 50 & 308 & 50 \\
\hline $\begin{array}{ll}\text { Mild } & \ldots \\
\text { Moderate } & \ldots \\
\text { Severe } & \ldots\end{array}$ & $\begin{array}{r}187 \\
103 \\
87\end{array}$ & $\begin{array}{r}18 \\
10 \\
8\end{array}$ & $\begin{array}{l}95 \\
40 \\
24\end{array}$ & $\begin{array}{r}22 \\
9 \\
5\end{array}$ & $\begin{array}{l}92 \\
63 \\
63\end{array}$ & $\begin{array}{l}15 \\
10 \\
10\end{array}$ \\
\hline Total & 1,059 & 100 & 440 & 100 & 619 & 100 \\
\hline
\end{tabular}

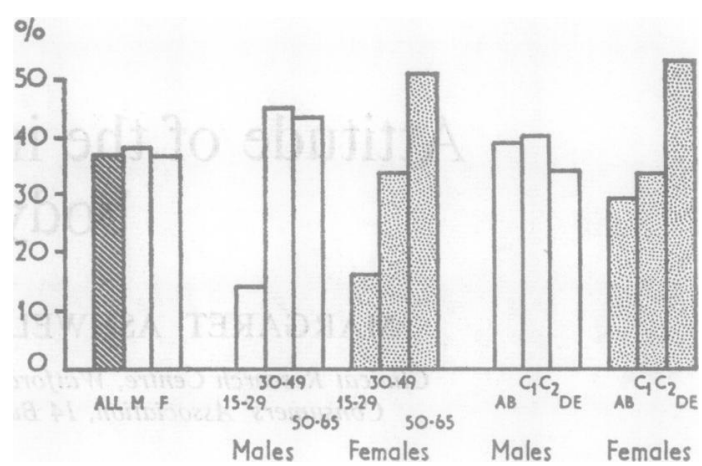

FIG. 1. Percentage of each group who are overweight $(>10 \%$ above ideal weight).

how this population was distributed according to weight class. Half of the population had weights which fell within the suitable weight range. More than one-third of the total sample had weights which were classed as overweight and only $14 \%$ of the total sample were classed as underweight. Figure 1 shows how the overweight people were distributed 5 according to sex, age, and social class groups. The groups which have the highest prevalence of over weight are women in the age group 50-65 and women in social classes D and E. A more detailed analysis of the actual height and weight data is found in the paper by Baird et al. (1974).

Attitude to Body Weight by Sex and Actual WeIGHT CATEgORY. The results of an analysis of the data to show how the members of these classes assessed their own body weight are shown in Figure 2. The sample was divided into six subgroups according to sex and actual weight class, i.e., underweight males and females, suitable weight males and females, and overweight males and females. The Figure shows the percentage of men and women in each weight class who considered themselves to be overweight, suitable weight or underweight.

Overweight people in the total sample were most accurate in the assessment of their weight class and underweight people were the least accurate. Of the overweight people, $81 \%$ gave a correct assessment of their weight compared with $64 \%$ of the suitable weight class and only $36 \%$ of the underweight class.

Comparing men and women in the sample, it can be shown that overweight women had a better idea of their own weight class than overweight men $(P<0.001) ; 89 \%$ of the women who were actually overweight considered themselves overweight, whereas only $69 \%$ of the overweight men considered themselves in this category. 


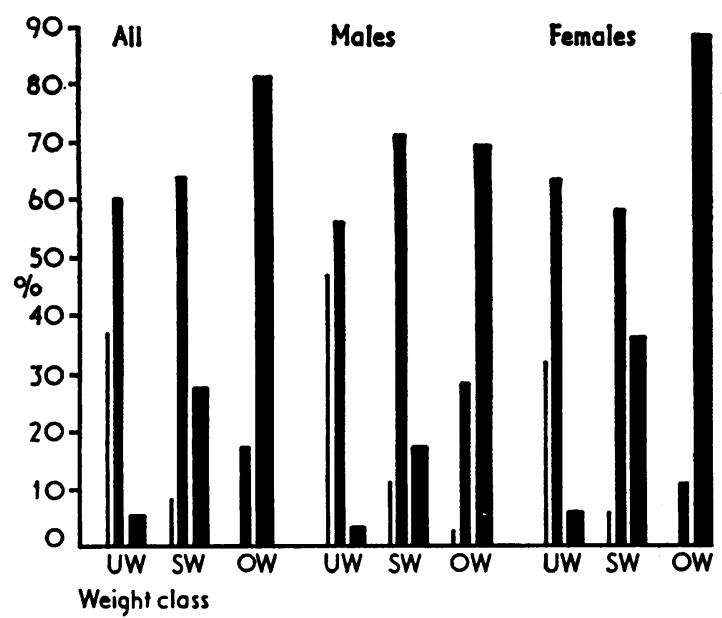

- $\%$ age who consider themselves underweight

\% oge who consider themselves suitable weight

$\%$ oge who consider themselves overweight

Fio. 2. Attitude to body weight-by actual weight classes.

Comparing men and women who were actually in the suitable weight category, it is clear that the women tended to overestimate their weight more than the men $(P<0.001), 36 \%$ thinking that they were overweight compared with only $17 \%$ of the men.

Attitude to Body Weight by Age and Social Class. Females. As shown in Figure 1, the prevalence of obesity in females rises steeply with age. Of the women in the 50-65 age group, 50.2\% were classified as overweight $(17.1 \%$ of these were severely overweight) whereas only $15.7 \%$ of women in the 15-29 age group were overweight (3.4\% severely overweight). There was also a dramatic increase in obesity among lower social class women (classes D and E); $51.6 \%$ of women in this group were overweight $(16.8 \%$ severely overweight $)$ compared with $28.5 \%$ of women in social classes $A$ and $B$ who were overweight $(10.6 \%$ severely overweight).

We were interested to see how the women in these two groups with a particularly high prevalence of obesity assessed their body weight. Figure 3 shows the percentage of women within each group who considered themselves to be underweight, suitable weight or overweight. It can be seen that of the overweight women in the 50-65 age group, $84 \%$ considered themselves to be overweight, whereas $95 \%$ and $93 \%$ of overweight women in the age groups $15-29$ and $30-49$ considered themselves as overweight. Of the overweight women in social classes $\mathrm{D}$ and $\mathrm{E}, 85 \%$ considered themselves to be
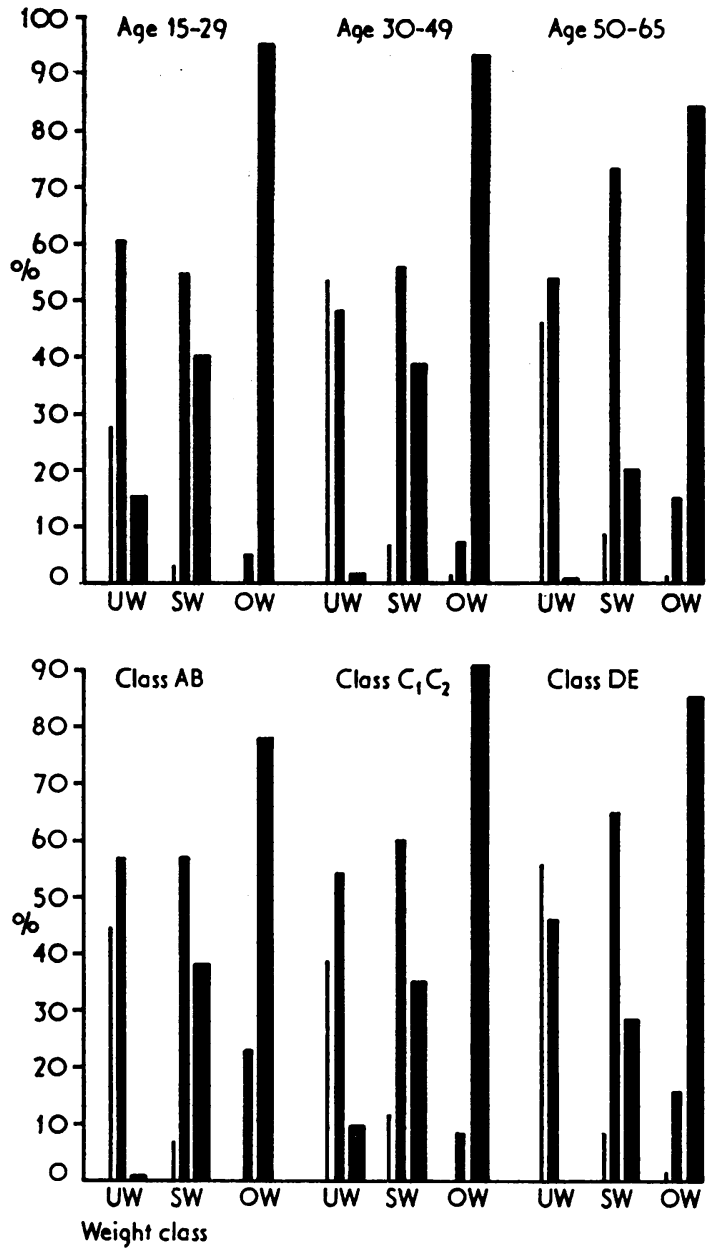

Fig. 3. Attitude to body weight-by actual weight classes within age and social class groups-females.

$\mathrm{UW}=$ underweight; $\mathrm{SW}=$ suitable weight; $\mathrm{OW}=$ overweight

overweight compared with $78 \%$ of overweight women in classes A and B and $90 \%$ of overweight women in classes $\mathrm{C}^{1}$ and $\mathrm{C}^{2}$.

Therefore it does seem that the vast majority of overweight women are aware of their size, whatever their age or social class.

Males. Figure 1 shows that for men, as for women, the youngest age group was again the one with the smallest proportion of overweight people $(14 \cdot 2 \%)$. However, the other two age groups contain similar proportions of overweight men $(45 \cdot 0 \%$ in the $30-49$ age group and $43 \cdot 3 \%$ in the 50-65 age group).

Unlike the women, there is no significant difference in the proportions of overweight men in each group when divided by social class. 

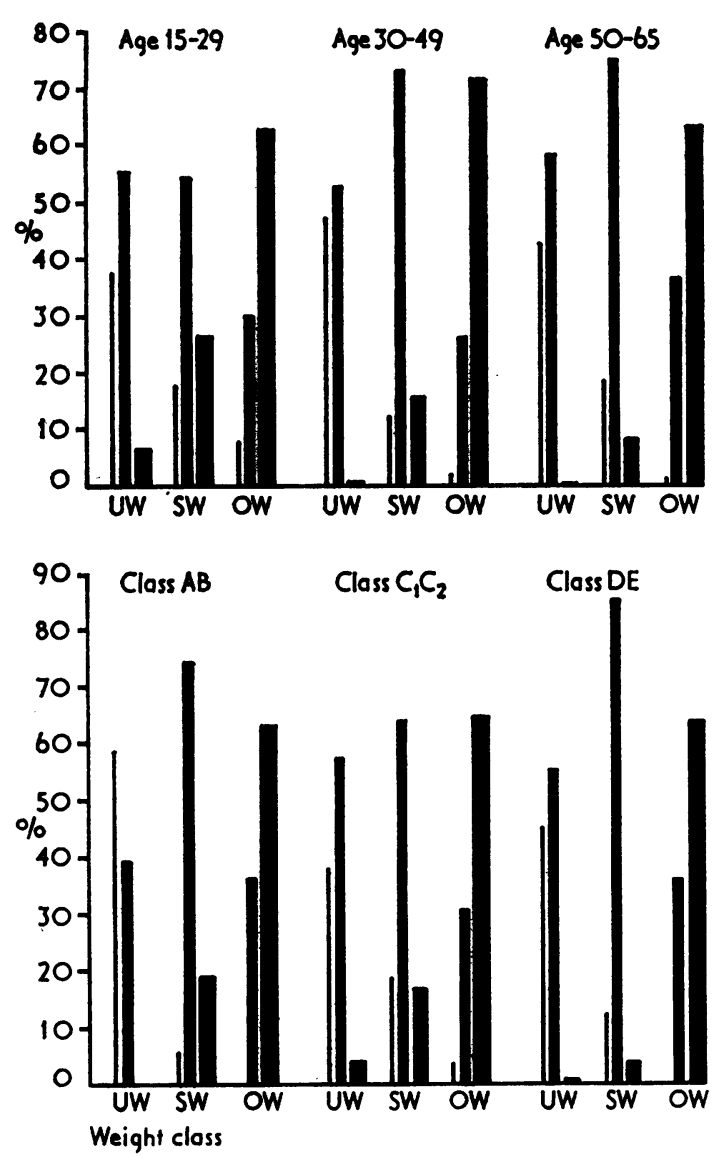

FIG. 4. Attitude to body weight-by actual weight classes within age and social class groups-males.

The results in Figure 4 show that there are very few differences in the proportions of overweight men who considered themselves overweight within each age class. Of the overweight men in the 15-29 age group, $62 \%$ considered themselves overweight compared with $73 \%$ in the $30-49$ and $63 \%$ in the 50-65 age groups. The differences between overweight men in the different social class groups are even smaller: $63 \%$ of overweight men in classes $A$ and $\mathrm{B}$ considered themselves overweight compared with $65 \%$ in classes $\mathrm{C}^{1}$ and $\mathrm{C}^{2}$ and $64 \%$ in classes $\mathrm{D}$ and $\mathrm{E}$.

AtTempts to Lose Weight. Total Sample. Twofifths of the total sample had tried to lose weight at some time. Half of the women and only a quarter of the men had tried to lose weight. Men in the 30-65 age group had made more attempts than younger men, and men in social classes A and B had made more attempts to lose weight than men in lower classes. Age and social class did not make any significant difference for women.

The total sample was divided by actual weight class so that it was possible to obtain data about the number of overweight people who had made attempts to reduce.

Overweight People. Figure5 shows the percentage of overweight people within each sex, age, and

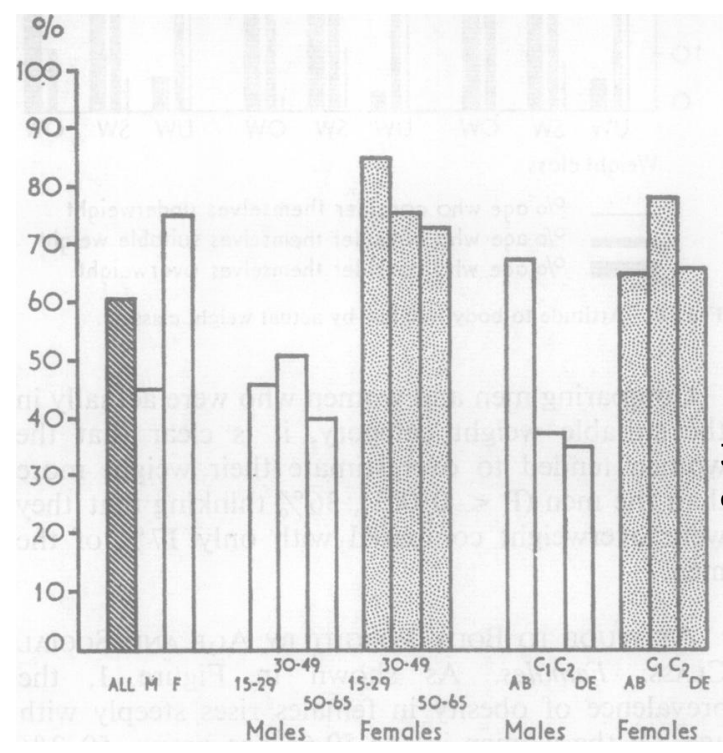

Fig. 5. Percentage of overweight people who have tried to lose weight.

social class group who said that they had tried to lose weight at some time; $61 \%$ of all the overweight people had done so. Overweight women (73\%) were far more likely to have tried to lose weight than men $(P<0.001)$. The overweight men who were most likely to have tried to lose weight were the ones belonging to social classes $A$ and $B ; 68 \%$ of the men in this group had made attempts to lose weight at some time. There was no significant difference between the proportion of overweight women in the different age groups who had tried to lose weight, but the proportion of women who had attempted to lose weight was greater in social classes $C^{1}$ and $C^{2}$ than in other classes $(P<0.01)$.

\section{The Consumers' Association Survey}

Actual Weight Distribution. The respondents to the Consumers' Association questionnaire all claimed experience of slimming and it was, 
TABLE II

CLASSIFICATION OF WEIGHT CLASS : THE CONSUMERS' ASSOCIATION SURVEY

\begin{tabular}{|c|c|c|c|c|c|c|}
\hline \multirow{2}{*}{$\begin{array}{l}\text { Actual Weight } \\
\text { Class-Current }\end{array}$} & \multicolumn{2}{|c|}{ All } & \multicolumn{2}{|c|}{ Males } & \multicolumn{2}{|c|}{ Females } \\
\hline & No. & $\%$ & No. & $\%$ & No. & $\%$ \\
\hline $\begin{array}{l}\text { Underweight } \\
\text { Normal weight } \\
\text { Overweight } \quad \text {.. }\end{array}$ & $\begin{array}{r}57 \\
1,138 \\
978\end{array}$ & $\begin{array}{r}3 \\
52 \\
45\end{array}$ & $\begin{array}{r}9 \\
217 \\
201\end{array}$ & $\begin{array}{l}2 \\
51 \\
47\end{array}$ & $\begin{array}{r}48 \\
921 \\
777\end{array}$ & $\begin{array}{r}3 \\
53 \\
44\end{array}$ \\
\hline Total & 2,173 & 100 & 427 & 100 & 1,746 & 100 \\
\hline
\end{tabular}

therefore, not surprising that their heights and current weights showed the distribution in Table II. About half the sample were now classified as suitable weight and about half were still overweight. Very few were classified as underweight.

IDEAL WeIGHT. Table III shows how the ideal weights given by the respondents would be classified according to the life insurance figures, $80 \%$ of all the ideal weights falling within the suitable weight range. Only $10 \%$ of the women gave an ideal weight in the overweight range compared with $21 \%$ of the men. Women, therefore, seemed more likely than men to choose a weight associated with low mortality $(P<0.001)$. People whose current weights were within the suitable range had a better concept of their ideal weight than people who were still in the overweight range $(\mathrm{P}<0.001)$.

TABLE III

CLASSIFICATION OF IDEAL WEIGHTS: THE CONSUMERS' ASSOCIATION SURVEY

\begin{tabular}{|c|c|c|c|c|c|c|}
\hline \multirow{2}{*}{$\begin{array}{l}\text { Ideal Weight } \\
\text { Classified }\end{array}$} & \multicolumn{2}{|c|}{ All } & \multicolumn{2}{|c|}{ Males } & \multicolumn{2}{|c|}{ Females } \\
\hline & No. & $\%$ & No. & $\%$ & No. & $\%$ \\
\hline $\begin{array}{l}\text { Underweight .. } \\
\text { Suitable weight } \\
\text { Overweight }\end{array}$ & $\begin{array}{r}172 \\
1,702 \\
254\end{array}$ & $\begin{array}{r}8 \\
80 \\
12\end{array}$ & $\begin{array}{r}19 \\
313 \\
87\end{array}$ & $\begin{array}{r}4 \\
75 \\
21\end{array}$ & $\begin{array}{r}153 \\
1,389 \\
167\end{array}$ & $\begin{array}{l}9 \\
81 \\
10\end{array}$ \\
\hline Total & 2,128 & 100 & 419 & 100 & 1,709 & 100 \\
\hline
\end{tabular}

\section{Discussion}

In comparing our results with previous surveys (Silverstone, 1968; Osancova and Hejda, 1970) it must be remembered that our classification of an overweight person was defined as one who exceeded his or her ideal weight by more than $10 \%$. Since only $11 \%$ of our overweight women and $31 \%$ of our overweight men denied being overweight, these results, as they stand, can be interpreted as showing a better awareness of overweight in our sample than either of the previous surveys. If our overweight group is analysed, restricting attention to individuals who exceeded their ideal weight by more than $30 \%$ (as in Silverstone's study), then the increased awareness of overweight in our sample is even more obvious. Only 1 out of 25 of the men and 2 out of 68 of the women denied being overweight compared with one-third of the obese men and one-fifth of the obese women in Silverstone's study.

Most of the people in our broad overweight group who denied being overweight were those who were between 11 and $20 \%$ overweight. Estimates of suitable weight were made on the assumption that each subject was of medium frame. Therefore, the weight of large-framed subjects was underestimated and that of small-framed subjects overestimated. It is quite possible that somebody classified as between 11 and $20 \%$ overweight on our definition would in fact be at the upper end of the suitable weight range and certainly not classed as medically overweight. With this reservation in mind, we believe that our results show a very good level of awareness of overweight within our sample and imply that the people who are overweight have not become like this simply because they do not realize it.

The overweight women in our survey were more aware of their weight than the overweight men, a finding which confirmed Silverstone's and Osancova's results. Dwyer and Mayer's (1970) analysis of several national public opinion polls also revealed that women were more concerned about their weight than men.

It is difficult to make a direct comparison between our findings and those of McKenzie (1967) because he asked his 2,000 slimmers only about their attempts to reduce weight during the preceding year. Therefore the fact that the percentage of our sample who said that they had tried to lose weight at some time was higher than the percentage of his sample who had tried to lose weight during the previous year (35\% of women and $15 \%$ of men) might reflect only that our subjects were delving deeper into the past. The older men in our sample were more likely than the younger men to have made attempts to lose weight and this could be explained by the fact that they had lived longer. However, McKenzie found this result too, and his question referred only to the 'past year'. Also, there was no age difference in the total number of our women who had tried to lose weight.

\section{Can Attitude to Weight explain the Prevalence OF OVERWEIGHT?}

Figure 1 showed how the percentage of overweight people varied in the different demographic groups. We were interested to see whether the 
attitude to weight and attempts to lose weight were different between the groups and whether this might explain why the prevalence of overweight was higher in some groups than in others. The groups with the highest prevalence of overweight were the women in the 50-65 age group and social classes $D$ and $E$. Therefore, if any differences existed in attitude to weight which resulted in a high prevalence of overweight in the group, we would expect to find them in these two groups.

As far as awareness of weight is concerned, only $16 \%$ of the overweight women in the 50-65 age group and $15 \%$ of the overweight women in the $\mathrm{D}$ and $\mathrm{E}$ class group denied being overweight, and most of these women were not severely overweight. Therefore most of the overweight women in these groups are well aware of their size.

As far as attempts to lose weight are concerned, at least two-thirds of the overweight women in both groups have made some attempt to lose weight. Exactly how serious these attempts were it is impossible to say, but it is reasonably encouraging that any attempt at all has been made by the majority of these women because it indicates at least a desire to be slimmer.

So, if awareness of weight and attempts to lose weight are not dissimilar among the groups for the two sexes, how do some groups emerge with a higher prevalence of overweight than others? Social pressures obviously explain this to a certain extent. Both young men and young women know that they can have a wider choice of fashionable clothes to wear, thus making them more attractive if they keep slim, whereas older people are perhaps not motivated in this way. The same argument could be used to explain the difference seen between the social classes in women. In other words, although the older people and lower social class women might be aware of their size and might say that they have made attempts to lose weight, their success at losing weight might be poorer because their motivation is poorer.

A further reason for the lack of success of certain groups might be that the effort they have to make to reduce weight by dieting has to be even greater because they take very little exercise. Younger people are more likely to be more active and therefore have a higher energy expenditure, on average, than older people. With increasing age, the probability of a mainly sedentary life is greater and, taken together with the likelihood of the greater availability and appreciation of good food, a positive energy balance can soon be established. Also, it is likely that a vicious circle sets in and the fatter people get, the less exercise they take. The contribution of voluntary energy expenditure to the energy output side of the energy balance equation might also help to explain why there is no difference in the prevalence of overweight between the social classes in men. The men in social classes D and E, although probably not having the same social motivation to be slim as the upper class men, might stand less chance of becoming overweight because many of them will have increased energy expenditure due to their heavy manual jobs. Lower social class women, on the other hand, often lack the motivation to be slim, probably take no more exercise than women of higher social class, and think they can consume the same amount of food and drink as their husbands.

This study was carried out by the Consumers' Association in collaboration with the Overweight and Heart Disease Research Trust in an investigation of the Prevalence of Obesity in a London Borough. We gratefully acknowledge the help given by Dr. J. T. Silverstone and Dr. I. McLean Baird, and we thank the Consumers' Association for allowing us access to the data in order to publish this paper.

We should also like to thank Miss Susan Insole of the Consumers' Association for her help with the survey and Mr. Patrick Brennan, M.Sc., of Northwick Park Hospital, Harrow, who handled the computer data.

\section{REFERENCES}

Baird, I. Mclean, Silverstone, J. T., Grimshaw, J. J. and Ashwell, M. A., (1974). Prevalence of obesity in a London borough. Practitioner (In press).

DWYer, J. T. and MAYER, J. (1970). Attitudes toward body weight and dieting behaviour. Potential dieters: Who are they? J. Amer. diet. Ass., 56, 510.

McKenzie, J. C. (1967). Profile on slimmers. J. Market Research Soc. (Commentary), 9, 77.

Metropolitan Life Insurance Company (1959). Overweight: its prevention and significance. Statist. Bull. No. 40.

MoNK, D. (1971). Social grading on the national readership survey. Joint Industry Committee for National Readership Surveys.

MONTEGRIFFo, V. M. E. (1968). Height and weight of a United Kingdom adult population with a review of anthropometric literature. Ann. hum. Genet., 31, 389.

Osancova, K. and Hejda, S. (1970). Nutrition and attitude to obesity: epidemiological survey in a population with a high prevalence to obesity. Rev. Czechoslovak. Med., 16, 131.

Silverstone, J. T. (1968). Psychosocial aspects of obesity. Proc. roy. Soc. Med., 61, 371. 